УДК 624.131 .7

ИНЖЕНЕРНО-ГЕОЛОГИЧЕСКОЕ ОБЕСПЕЧЕНИЕ УСТОЙЧИВОСТИ ШТАБЕЛЯ КУЧНОГО ВЫЩЕЛАЧИВАНИЯ

\author{
Поморцева А.А., Карасев М.А., Поспехов Г.Б. \\ ФГБОУ ВО «Санкт-Петербургский горный университет», Санкт-Петербург, \\ e-mail: a.a.pomortseva@mail.ru
}

\begin{abstract}
Применение технологии кучного выщелачивания на сегодня является актуальной практикой в добывающей промышленности по всему миру благодаря своей рентабельности, высокой эффективности и низким капитальным затратам. Кучное выщелачивание позволяет максимально эффективно использовать как отходы горнорудного производства, так и забалансовые запасы месторождений с целью извлечения полезного компонента даже при низком и некондиционном его содержании. Многолетняя практика работы зарубежных предприятий, использующих метод кучного выщелачивания, подтверждает его высокую технико-экономическую эффективность по сравнению с традиционными фабричными технологиями. Технология кучного выщелачивания имеет специфические особенности и определенные риски, как для окружающей среды, так и для безопасности труда при ее применении. При проектировании штабелей кучного выщелачивания первоочередное значение имеют инженерно-геологические процессы, поскольку именно они определяют фактическую устойчивость штабеля и являются ключевыми с точки зрения эффективной, надежной и безопасной эксплуатации штабеля кучного выщелачивания. В данной работе рассмотрена расчетная схема развития напряженно-деформированного состояния штабеля выщелачивания, выполнена оценка устойчивости техногенного массива по двум основным расчетным сечениям, ориентированным вдоль и поперек отвала с использованием двух отдельных программных комплексов Plaxis и Slide. При выполнении моделирования учтены различные варианты формирования напряженного состояния отвала техногенного массива кучного выщелачивания, которые включают изменение напряженного состояния отвала в результате передачи нагрузки от транспортного оборудования, изменения напряженного состояния при его насыщении растворами. Сделаны прогнозные оценки поведения массива штабеля в период его сооружения и эксплуатации.
\end{abstract}

Ключевые слова: штабель кучного выщелачивания, напряженно-деформированное состояние, оценка устойчивости, инженерно-геологический прогноз, моделирование геомеханических процессов

\title{
ENGINEERING AND GEOLOGICAL SUPPORT OF THE STABILITY OF THE HEAP LEACH PAD
}

\begin{abstract}
Pomortseva A.A., Karasev M.A., Pospekhov G.B.
Saint-Petersburg Mining University, Saint Petersburg, e-mail: a.a.pomortseva@mail.ru

The use of the heap leach pads today is a relevant practice in the mining industry around the world due to its profitability, high efficiency and low capital costs. The technology of heap leaching allows to use both mining waste and off-balance reserves of deposits in order to extract a useful component much more efficiently even with its low and substandard content. Long-term practice of foreign enterprises using the heap leaching method confirms its high technical and economic efficiency in comparison with traditional factory technologies. However, today the heap leaching technology cannot be considered as a perfect one due to the specific features of the technology itself which includes certain risks both for the environment and for labor safety. In the design and construction of the heap leach pads geomechanical processes have the primary importance, since they determine the actual stability of the stack and are the key for the effective, reliable and safe exploitation of the heap leach pad. A design of the scheme for the development of the stress and strain state of the leach stack was developed, the stability of the technogenic massif was assessed. in two main design sections oriented along and across the stack using two separate Plaxis and Slide software systems. Various options for the formation of the stress state of the heap leaching stack were taken into account in simulation model, which include the change in the stress state of the stack as a result of applied load from the transport equipment and the change in the stress state when the mass is saturated with solutions. The stability coefficient for various design cases are determined. Predictive estimates of the behavior of the stack mass during its construction and operation were made.
\end{abstract}

Keywords: heap leach pad, stress and strain state, stability assessment, engineering and geological forecast, modeling of geomechanical processes

В связи с уменьшением запасов богатых золотосодержащих руд и увеличением объемов нетрадиционного сырья, бедных и забалансовых руд, технология кучного выщелачивания находит все более широкое применение для извлечения полезного компонента из низкосортных руд в силу ее высокой рентабельности, особенно в золотодобывающей промышленности [1-3]. $\mathrm{C}$ применением данной технологии отходы горнорудного производства, складируемые в отвалы, рассматриваются как техногенные месторождения различных видов металлов, что отвечает современным принципам устойчивого развития [4]. Основным принципом технологии кучного выщелачивания является миграция раствора цианида натрия через неподвижный объем предварительно раздробленной до крупности 120 мм, а затем окомкованной с добавлением цемента руды. В результате чего по пути движения раствора происходит окисление металлов за счет их взаимодействия с химическими реагентами, металлы преобразуются 
в легкорастворимые соединения и остаются в растворе, из которого в последующем легко извлечь полезный компонент. В связи с этим основание конструкции массива штабеля выщелачивания устраивается под углом наклона $1-3^{\circ}$ для последующего эффективного сбора продуктивного раствора. Главным достоинством технологии является относительно низкая стоимость извлечения полезного компонента $[2,5]$. При использовании данной технологии возникает ряд трудностей, ввиду различных инженерно-геологических факторов, влияющих на прогнозирование и обеспечение устойчивости техногенного сооружения. В связи с этим в качестве главного инструмента при проектировании работ по кучному выщелачиванию на сегодняшний день применяется численное моделирование развития напряженно-деформированного состояния штабеля выщелачивания. Результаты моделирования являются главным основанием для разработки надежных проектных решений для безопасного сооружения и эксплуатации техногенного массива штабеля кучного выщелачивания [6]. Однако при моделировании возникают затруднения, связанные с учетом изменений параметров физико-механических свойств техногенных грунтов, слагающих массив штабеля, обусловленных химическим процессом выщелачивания грунтов, его значительной продолжительностью, уплотнением техногенных грунтов под действием гравитации и собственного веса, а также насыщением растворами цианида и атмосферными осадками [7, 8]. Все это приводит к изменению параметров физико-механических свойств, в том числе и к снижению прочностных характеристик грунтов штабеля выщелачивания [9]. Таким образом, для повышения надежности прогнозирования инженерно-геологических условий эксплуатации техногенного массива штабеля кучного выщелачивания, требуется проведение лабораторных исследований, мониторинга изменения параметров свойств техногенных грунтов с моделированием развития напряженнодеформированного состояния на различных этапах строительства и эксплуатации штабеля. В представленной работе численное моделирование напряженно-деформированного состояния произведено на основе результатов лабораторных испытаний грунтов техногенного массива штабеля в их изначальном состоянии, до укладки в штабель и обработки растворами цианида, представляет собой предварительное моделирование для обоснования проектных параметров принятой конструкции штабеля.

Целью исследования являлась разработка алгоритма инженерно-геологического обеспечения устойчивости массива кучного выщелачивания посредством оценка напряженно-деформированного состояния массива штабеля кучного выщелачивания на стадиях его сооружения и эксплуатации, а также расчета локальной и общей устойчивости штабеля и выявление закономерностей потери устойчивости.

Основной метод исследования заключался в математическом моделировании развития напряженно-деформированного состояния отвала штабеля методами механики сплошной среды [10].

Конструкция штабеля кучного выщелачивания представляет собой четырехъярусное сооружение, сложенное окомкованной рудой, отсыпка которой производится механизированным способом. Отвал состоит из ярусов высотой 10 м, которые разделены на панели, панели друг от друга отделяются разделительным дамбами высотой 2 м. Для эффективного сбора продуктивного раствора наклон основания при устройстве штабелей кучного выщелачивания согласно промышленной отечественной и зарубежной практике обычно принимается в поперечном направлении $3^{\circ}$, в продольном направлении $1^{\circ}$.

Основные конструктивные параметры штабеля кучного выщелачивания представлены на рис. 1.

Основой численного алгоритма расчета параметров напряженного состояния штабеля кучного выщелачивания стали результаты лабораторных испытаний образцов грунтов основания штабеля и грунта, слагающего массив штабеля. Характеристики грунтов основания и самого штабеля представлены в табл. 1 и 2. От правильности выбора и выполнения лабораторных испытаний грунтов зависит надежность прогноза инженерно-геологической, горно-геомеханической обстановки и поведения пород штабеля с учетом проектных нагрузок, основанного на численном моделировании формирования напряженно-деформированного состояния грунтов штабеля [11]. Для идентификации физико-механических свойств грунтов применялись испытания по определению гранулометрического состава грунта согласно ГОСТ 12536-2014 и плотности минеральной части согласно ГОСТ 5180-2015, по их результатам были получены: плотность грунтов при естественной влажности, 
плотность при полном водонасыщении, коэффициент пористости. По результатам испытаний техногенных грунтов при прямом (одноплоскостном) срезе и компрессионных испытаний согласно ГОСТ 12248 2010 а также расчетными методами были получены модуль деформации грунта, одометрический модуль деформации грунта, модуль упругости, коэффициент поперечной деформации, сцепление, угол внутреннего трения, угол дилатансии (табл. 1,2$)$.

В качестве моделей деформирования сред при выполнении расчетов оценки устойчивости отвала кучного выщелачивания приняты модель Кулона - Мора для описания механического поведения грунтов основания и грунтов сооружения и модель упрочняющегося грунта (Hardening soil model) для описания механического поведения окомкованной руды. Hardening soil model (упругопластическая модель с изотропным упрочнением) используется для всех видов дисперсных грунтов, как песчаных, так и глинистых. В отличие от модели Кулона - Мора, данная модель использует гиперболическую зависимость деформаций от напряжений, что более точно описывает реальное поведение грунтов и учитывает упрочнение грунта при увеличении уровня напряжений, то есть описывается зависимость модулей деформации от напряжений [12].

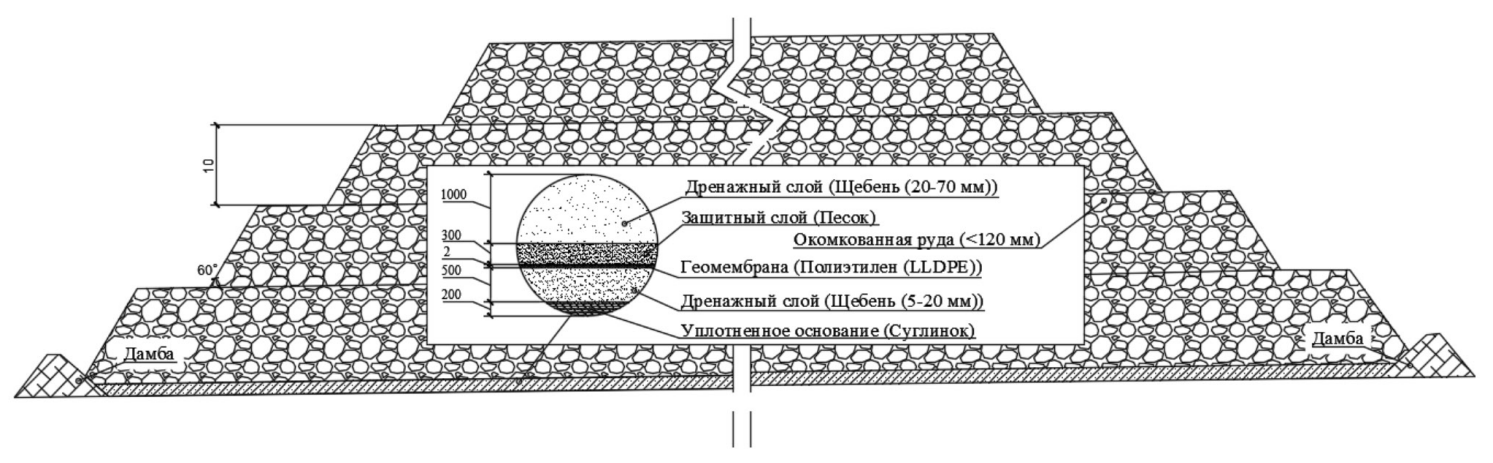

Рис. 1. Схема техногенного массива штабеля кучного выщелачивания в поперечном направлении

Таблица 1

Параметры модели Кулона - Мора для грунтов основания и сооружения

\begin{tabular}{|c|c|c|c|c|c|c|c|}
\hline Наименование грунта & $\begin{array}{c}\gamma_{\text {unsat }}, \\
\mathrm{\kappa H} / \mathrm{M}^{3}\end{array}$ & $\begin{array}{c}\gamma_{\text {sat }}, \\
\mathrm{KH} / \mathrm{M}^{3}\end{array}$ & $e$ & $\begin{array}{c}E_{0}, \\
\text { МПа }\end{array}$ & $v_{0}$ & $c^{\prime}$, кПа & $\varphi^{\prime},{ }^{0}$ \\
\hline \multicolumn{8}{|c|}{ Грунты основания } \\
\hline $\begin{array}{l}\text { Суглинок дресвяный с примесью торфа, } \\
\text { мягкопластичный }\end{array}$ & 15,6 & 18,4 & 0,73 & 10,0 & 0,35 & 18 & 20 \\
\hline \multicolumn{8}{|c|}{ Грунты штабеля } \\
\hline Тело дамбы & 21,0 & 22,0 & 0,32 & 40,0 & 0,40 & 10 & 35 \\
\hline Противофильтрационный элемент & 17,5 & 20,5 & 0,05 & 15,0 & 0,40 & 5 & 15 \\
\hline Защитный слой из щебенистого грунта & 22,0 & 24,0 & 0,73 & 40,0 & 0,40 & 5 & 40 \\
\hline
\end{tabular}

Параметры модели Hardening soil для грунтов штабеля

Таблица 2

\begin{tabular}{|c|c|c|c|c|c|c|c|c|c|}
\hline $\begin{array}{c}\gamma_{\text {unsat }}, \\
\kappa \mathrm{H} / \mathrm{M}^{3}\end{array}$ & $\begin{array}{c}\gamma_{s a t}, \\
\kappa \mathrm{H} / \mathbf{M}^{3}\end{array}$ & $e$ & $E_{0}, \mathrm{MПа}$ & $\begin{array}{l}E_{\text {oed }} \\
\text { МПа }\end{array}$ & $E_{u r}, \mathrm{M \Pi а}$ & $\mathrm{m}$ & $c^{\prime}$, кПа & $\varphi^{\prime},{ }^{0}$ & $\psi,{ }^{0}$ \\
\hline 15,6 & 17,3 & - & 10 & 6,5 & 30 & 0,6 & 40 & 31 & 0 \\
\hline
\end{tabular}

П р и м е ч а н и е $\gamma_{\text {unsat }}-$ плотность грунта при естественной влажности; $\gamma_{\text {sat }}$ - плотность грунта при полном водонасыщении; $e$ - коэффициент пористости; $E_{0}-$ модуль деформации грунта; $E_{\text {oed }}-$ одометрический модуль деформации грунта; $E_{u r}$ - модуль упругости грунта; $v_{0}-$ коэффициент поперечной деформации грунта; $m$ - показатель, учитывающий влияние средних напряжений на деформационные свойств грунта; $c^{\prime}-$ эффективное сцепление; $\varphi^{\prime}$ - эффективный угол внутреннего трения; $\psi$ - угол дилатансии. 
Расчет устойчивости отвалов выполнялся для двух основных расчетных случаев. Первый расчетный случай - стадия строительства, характеризующая напряженное состояние отвала в процессе его формирования. Вторая стадия - стадия эксплуатация, характеризующая изменение напряженного состояния тела отвала в процессе выщелачивания руды. В процессе строительства тело отвала и грунты основания находятся в сухом состоянии. На стадии эксплуатации грунты, расположенные ниже уровня подземных вод, принимались как полностью водонасыщенные, грунты, расположенные выше грунтовых вод, принимались как полностью сухие.

Расчет устойчивости выполнялся на основании численного моделирования в плоско-деформационной постановке в программном комплексе Plaxis постановке по двум расчетным сечениям (рис. 2). При прогнозе напряженного состояния отвала учитывались стадийность формирования ярусов отвала, нагрузка от транспортного оборудования, обводненность растворами выщелачивания тела отвала. Процесс формирования отвала сопровождается деформированием руды, что приводит к изменению геометрической конфигурации отвала за счет уплотнения руды [13]. Дополнительно в программном комплексе Slide (метод предельного равновесия) выполнена про-

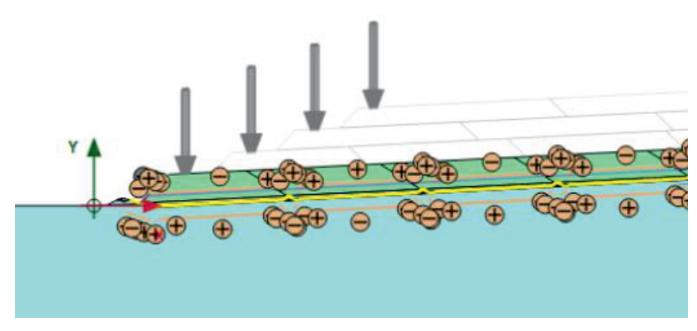

1

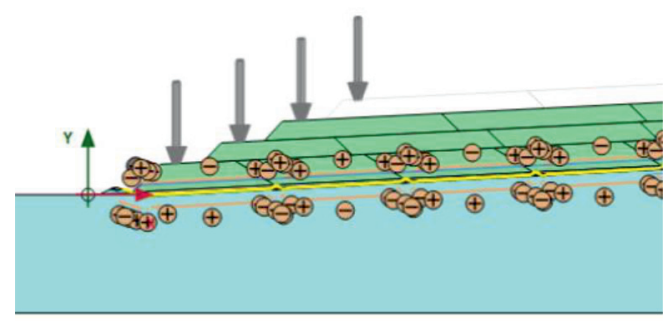

3 верка устойчивости отвала в его исходной конфигурации, без учета уплотнения рудной массы.

При расчете напряженно-деформированного состояния в процессе формирования ярусов отвала штабеля кучного выщелачивания было принято 4 стадии формирования напряженного состояния, каждая из которых соответствует формированию ярусов отвала штабеля. В зависимости от принятой расчетной схемы (стадия строительства, стадия эксплуатации) условия обводненности тела отвала штабеля кучного выщелачивания изменялись.

Оценка устойчивости отвала была выполнена по двум формам потери устойчивости - местной (локальной) и общей. Под местной устойчивостью понимается потеря устойчивости в рамках локального участка, яруса отвала или минимальное значение коэффициента устойчивости по всему отвалу. Под общей устойчивостью понимается потеря устойчивости отвала, когда поверхность скольжения проходит через все четыре яруса отвала и может привести к катастрофическим последствиям, при этом при обеспечении общей устойчивости местная устойчивость может быть не обеспечена [14]. Оценка общей устойчивости отвала штабеля кучного выщелачивания выполнена в программном комплексе Slide.

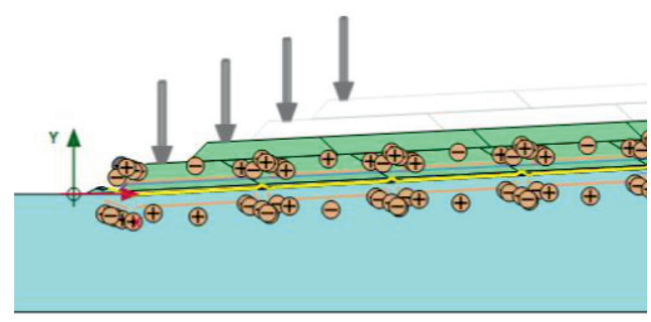

2

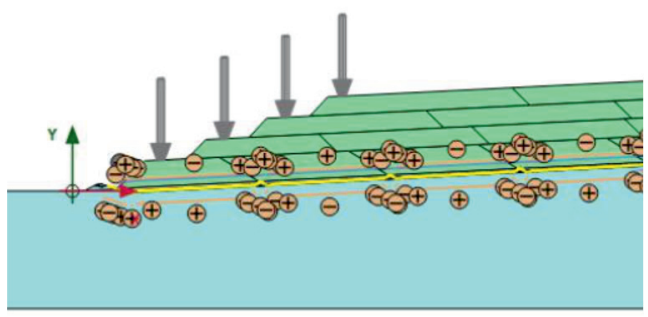

4

Рис. 2. Стадии численного моделирования формирования напряженного состояния штабеля кучного выщелачивания (поперечное сечение) 
Результаты оценки устойчивости отвала штабеля кучного выщелачивания согласно принятым расчетным схемам сведены в табл. 3. Результаты оценки общей устойчивости отвала представлены в табл. 4.

Таблица 3

Оценка местной устойчивости отвала на стадии строительства

\begin{tabular}{|l|c|c|c|c|}
\hline \multirow{2}{*}{ Расчетное сечение } & \multicolumn{4}{|c|}{$\begin{array}{c}\text { Коэффициент запаса по устойчивости } \\
\text { при формировании яруса отвала }\end{array}$} \\
\cline { 2 - 5 } & I ярус & II ярус & III ярус & IV ярус \\
\hline \multicolumn{5}{|c|}{ Без нагрузки от транспорта } \\
\hline Поперечное сечение - I & $2,16(1,72)$ & $2,12(1,72)$ & $1,98(1,72)$ & $1,98(1,72)$ \\
\hline Продольное сечение - II & $2,18(1,87)$ & $2,16(1,87)$ & $2,13(1,87)$ & $2,01(1,87)$ \\
\hline \multicolumn{7}{|c|}{ С учетом нагрузки от транспортного оборудования } \\
\hline Поперечное сечение - I & $1,57(1,44)$ & $1,76(1,73)$ & $1,97(1,82)$ & $1,90(1,82)$ \\
\hline Продольное сечение - II & $1,80(1,53)$ & $1,95(1,84)$ & $1,99(1,85)$ & $1,93(1,80)$ \\
\hline
\end{tabular}

Пр и м еч ан и е. Вне скобок приведены результаты оценки устойчивости в программном комплексе Plaxis, учитывающие изменение конфигурации отвала в процессе его уплотнения; в скобках приведены результаты оценки устойчивости отвала методом предельного равновесия, не учитывающие изменение начальной конфигурации тела отвала в процессе уплотнения.

Общая устойчивость откоса

Таблица 4

\begin{tabular}{|c|c|c|c|c|c|}
\hline \multirow{2}{*}{$\begin{array}{l}\text { Расчетное } \\
\text { сечение }\end{array}$} & \multicolumn{5}{|c|}{ Коэффициент запаса по устойчивости при различных схемах нагружения } \\
\hline & $\begin{array}{l}\text { Стадия стро- } \\
\text { ительства }\end{array}$ & $\begin{array}{c}\text { Стадия эксплу- } \\
\text { атации, режим } \\
\text { нормальной } \\
\text { эксплуатации }\end{array}$ & $\begin{array}{c}\text { Стадия эксплу- } \\
\text { атации, полное } \\
\text { водонасыщение } \\
\text { первого яруса }\end{array}$ & $\begin{array}{c}\text { Стадия эксплуатации, } \\
\text { полное водонасы- } \\
\text { щение всех ярусов, } \\
\text { с учетом перемычек } \\
\text { между ярусами }\end{array}$ & $\begin{array}{c}\text { Стадия эксплу- } \\
\text { атации, полное } \\
\text { водонасыщение } \\
\text { всех ярусов }\end{array}$ \\
\hline $\begin{array}{l}\text { Поперечное } \\
\text { сечение - I }\end{array}$ & 1,83 & 1,61 & 1,36 & 1,21 & 0,76 \\
\hline $\begin{array}{l}\text { Продольное } \\
\text { сечение - II }\end{array}$ & 1,94 & 1,88 & 1,52 & 1,42 & 0,91 \\
\hline
\end{tabular}

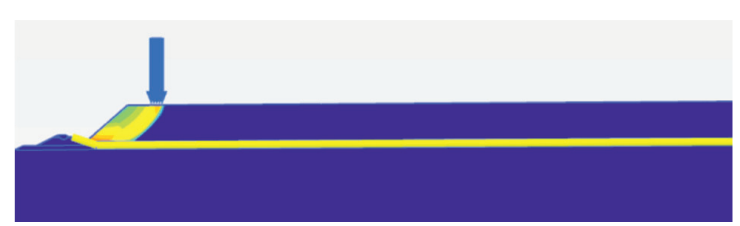

1

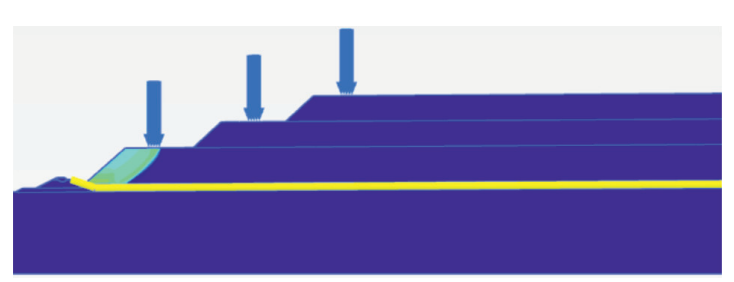

3

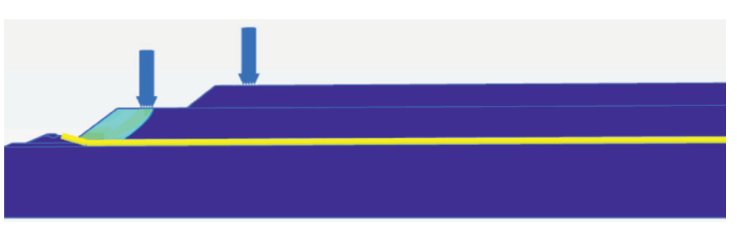

2

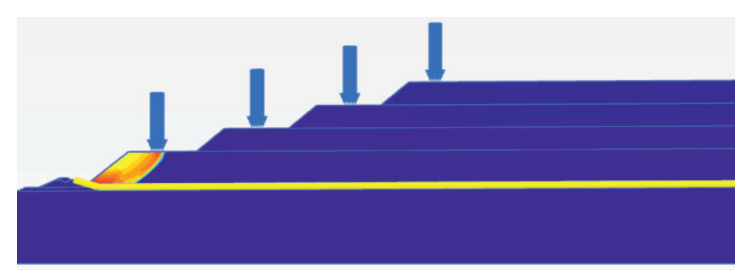

4

Рис. 3. Форма потери устойчивости штабеля кучного выщелачивания (продольное сечение, с учетом нагрузки от транспорта, стадия эксплуатации) 


\section{Заключение}

В данной статье рассматривается моделирование развития напряженно-деформированного состояния техногенного массива штабеля кучного выщелачивания. Основной целью исследования данной инженерно-геологической и геомеханической проблемы является разработка алгоритма инженерно-геологического обеспечения устойчивости техногенного массива штабеля кучного выщелачивании на основании численного инструмента, способного моделировать инженерно-геологическую и горно-геомеханическую обстановку участка кучного выщелачивания. Для более точных результатов моделирования и прогнозных оценок разработанная расчетная схема оценки устойчивости откосов техногенного массива штабеля должна максимально соответствовать условиям сооружения и эксплуатации техногенного массива штабеля выщелачивания. Отсыпка штабеля производится под углом, близким к углу естественного откоса. При этом в массиве устанавливается равновесие удерживающих и сдвигающих откос сил. Представленная модель демонстрирует, что поверхность скольжения локализуется в рамках яруса и не распространяется на весь штабель, это говорит о более высоком общем коэффициенте устойчивости штабеля ввиду того, что сдвигающие призмы сил активного давления не превышают внутренние силы сопротивления смещению пород штабеля. Высота яруса в 10 м является оптимальной и допустимой для обеспечения общей устойчивости штабеля. Из результатов исследования можно сделать вывод, что коэффициент запаса по устойчивости практически не изменяется по мере увеличения количества ярусов штабеля, от первого до четвертого. Локализация деформаций для всех расчетных вариантов происходит в окомкованной руде первого яруса, в породах первого яруса можно ожидать смещение пород штабеля от проектного положения, что требует специальных мер по поддержанию устойчивости первого яруса штабеля. В заключение стоит отметить, что для более точных прогнозов инженерно-гелогической, геомеханической обстановки на участках кучного выщелачивания численное моделирование напряженно-деформированного состояния техногенного массива необходимо осуществлять на основе алгоритма, учитывающего закономерности изменения физико-механических свойств горных пород под влиянием уплотнения массива под действием гравитации и веса вышележащих пород, насыщения грунтов массива растворами цианида и атмосферными осадками и последующее формирование массива с новыми механическими свойствами на основании мониторинга изменения физико-механических свойств грунтов в разные периоды эксплуатации штабеля с целью обоснования надежных инженерных решений по управлению устойчивостью штабеля кучного выщелачивания.

\section{Список литературы / References}

1. Татауров С.Б. Оценка эффективности извлечения золота при кучном выщелачивании окомкованной суглинистой руды в Сибири // Горный информационно-аналитический бюллетень. № 7. М.: МГТУ, 2007. 320 с.

Tataurov S.B. Assessment of gold recovery efficiency during heap leaching of pelletized loamy ores in Siberia. Gornyy informatsionno-analiticheskiy byulleten'. No. 7. M.: MGTU, 2007. 320 p. (in Russian).

2. Файзуллина М.И. Кучное выщелачивание благородных металлов. М.: Изд-во Академии горных наук, 2001. C. $161-168$.

Fayzullina M.I. Heap leaching of noble metals. M.: Izdvo Akademii gornykh nauk, 2001. P. 161-168 (in Russian).

3. Федотов П.К., Сенченко А.Е., Федотов К.В., Бурдонов А.Е. Исследования обогатимости сульфидных и окисленных руд золоторудных месторождений Алданского щита // Записки Горного института. 2020. Т. 242. С. $218-$ 227. DOI: 10.31897/PMI.2020.2.218.

Fedotov P.K., Senchenko A.E., Fedotov K.V., Burdonov A.E. Studies of enrich-ment of sulfide and oxidized ores of gold deposits of the Aldan shield // Zapiski Gornogo instituta. 2020. Vol. 242. P. 218-227. DOI: 10.31897/PMI.2020.2.218 (in Russian).

4. Гальперин А.М., Кутепов Ю.И., Круподеров В.С. Инженерно-геологическое обеспечение формирования и последующего использования отвальных массивов на горных предприятиях // Горный информационно-аналитический бюллетень (научно-технический журнал. 2015. № S1. C. $20-35$.

Galperin A.M., Kutepov Yu.I., Krupoderov V.S. Engineering and geological support for the formation and subsequent use of rock massifs in mining enterprises // Gornyy informatsionnoanaliticheskiy byulleten' (nauchno-tekhnicheskiy zhurnal). 2015. № S1. P. 20-35 (in Russian).

5. Фоменко А.А. Использование техногенных скоплений и забалансовых руд цветных металлов в контексте экономики природопользования // Горный журнал. 2013 № 2. C. $102-107$.

Fomenko A.A. Use of the technogenic accumulations and off-balance sheet ores of nonferrous metals in the context of economy of nature use // Gorny zhurnal. 2013. No. 2. P. 102107 (in Russian).

6. Трушко В.Л., Протосеня А.Г. Перспективы развития геомеханики в условиях нового технологического уклада // Записки Горного института. 2019. Т. 236. С. 162-166. DOI: 10.31897/PMI.2019.2.162.

Trushko V.L., Protosenya A.G. Prospects of Geomechanics Development in the Context of New Technological Paradigm // Zapiski Gornogo instituta. 2019. Vol. 236. P. 162-166. DOI: 10.31897/PMI.2019.2.162 (in Russian).

7. Сарапулова Г.И. Эколого-геохимическая оценка почв в зоне техногенных объектов // Записки Горного института. 2018. T. 234. C. 658-662. DOI: 10.25515/PMI.2018.6.658.

Sarapulova G.I. Environmental Geochemical Assessment of Technogenic Soils // Zapiski Gornogo instituta. 2018. Vol. 234. P. 658-662. DOI:10.25515/PMI.2018.6.658 (in Russian).

8. Petersen J. Heap leaching as a key technology for recovery of values from low-grade ores - A brief overview, Hydrometallurgy. 2015. P. 122. 
9. Лушников Я.В., Багазеев В.К. Определение физикомеханических свойств окатышей при формировании штабеля кучного выщелачивания // Горный журнал. 2013. № 8. C. $124-127$.

Lushnikov Ya.V., Bagazeev V.K. Determination of the physical and mechanical properties of the soil under the formation of the heap leaching stack // Gornyy zhurnal. 2013. No. 8. P. 124-127 (in Russian).

10. Господариков А.П., Зацепин М.А. Математическое моделирование нелинейных краевых задач геомеханики// Горный журнал. 2019. № 12. С. 16-20.

Gospodarikov A.P., Zatsepin M.A. Mathematical modeling of boundary problems in geomechanics // Gornyi Zhurnal. 2019. No. 12. P. 16-20 (in Russian).

11. Протосеня А.Г., Вербило П.Э. Изучение прочности на сжатие трещиноватого горного массива // Записки Горного института. 2017. Т. 223. C. 51-57. DOI: 10.18454 PMI.2017.1.51.

Protosenya A.G., Verbilo P.E. Research of Compression Strength of Fissured Rock Mass // Zapiski Gornogo Instituta. 2017. Vol. 223. P. 51-57. DOI: 10.18454/ PMI.2017.1.51 (in Russian).
12. Солодей И.И., Затылюк Г.А. Использование грунтовых моделей при численном моделировании подземных сооружений (48-55) // Восточно-Европейский научный журнал. 2019. № 48 (2). С. 48-55.

Solodey I.I., Zatylyuk G.A. The use of soil models in the numerical modeling of underground structures (48-55)// Vostochno-Yevropeyskiy Nauchnyy Zhurnal. 2019. Vol. 48 (2). P. 48-55 (in Russian).

13. Рогов Е.И., Рогов А.Е., Рыспанов Н.Б. Обоснование и оптимизация основных геотехнологических параметров при кучном выщелачивании металлов. М.: Горная книга, 2010. 48 c.

Rogov E.I., Rogov A.E., Ryspanov N.B. Justification and optimization of the main geotechnological parameters for metals heap leaching. M.: Gornaya kniga, 2010. 48 p. (in Russian).

14. Рудаев Я.И., Китаева Д.А., Мамадалиева М.А. Моделирование деформационного поведения горных пород // Записки Горного института. 2016. Т. 222. C. 816-822. DOI: 10.18454/PMI.2016.6.816.

Rudaev Ya.I., Kitaeva D.A., Mamadalieva M.A. Simulation of rock deformation behavior. Zapiski Gornogo instituta. 2016. Vol. 222. P. 816-822. DOI: 10.18454/PMI. 2016.6.816 (in Russian). 